\title{
Psicologia da Diferença, Relações Raciais e Formação da(o) Psicóloga(o)
}

\author{
Antonio Vladimir Félix-Silva ${ }^{1}$ \\ ${ }^{1}$ Universidade Federal do Piauí, PI, Brasil. \\ Jéssica Pereira Duque ${ }^{1}$ \\ ${ }^{1}$ Universidade Federal do Piauí, PI, Brasil.
}

\author{
Joice Silva dos Santos ${ }^{1}$ \\ ${ }^{1}$ Universidade Federal do Piauí, PI, Brasil. \\ Matheus Barbosa da Rocha ${ }^{1}$ \\ ${ }^{1}$ Universidade Federal do Piauí, PI, Brasil.
}

\author{
Ana Kalliny de Sousa Severo ${ }^{2}$ \\ ${ }^{2}$ Universidade Federal do Rio Grande do Norte, RN, Brasil.
}

\begin{abstract}
Resumo: Neste estudo, apresentamos um relato de pesquisa acerca de uma psicologia da diferença nas relações raciais, a fim de cartografar processos de subjetivação das relações raciais na formação da(o) psicóloga(o) e sua interface com a atuação profissional. Como métodos de pesquisa, utilizamos a cartografia, a participação observante, um círculo de cultura e duas rodas de conversa para produzir narrativas, relato e escrita de si em diário cartográfico. Para discussão e análise, realizamos um exercício ético-estético-poético e político, operando com ferramentas-conceitos da esquizoanálise e da epistemologia da decolonização. Como política dessa invenção, considera-se que: a) o pesquisador devém analisador/testemunha do lugar de fala das mulheres negras que compõem a cartografia a partir de sua representatividade; b) a presença de um número reduzido de negras(os) nos cursos da área da saúde é efeito da colonização da academia; c) a implicação ético-política $\mathrm{da}(\mathrm{o})$ psicóloga(o) emerge como dispositivo de enfrentamento ao racismo institucional; e que d) um movimento estudantil menor, ao devir comum minoritário, rompe com o instituído e instaura, de modo criativo, discussões que suscitam o debate em torno da psicologia nas relações raciais e de situações-problema que emergem do dispositivo interseccionalidade.
\end{abstract}

Palavras-chave: Cartografia, Racismo, Formação do Psicólogo, Lugar de Fala e Representatividade, Saúde das Minorias Étnicas.

\section{Psychology of the Difference, Race Relations and Psychologist's Training}

\begin{abstract}
This study presents a research report about a psychology of the difference in race relations, aiming to map the subjectivation processes of race relations in the psychologist's training and their interface with the professional performance. We used cartography, observant participation, a culture circle, and two conversation circles for narrative production, self-reporting and writing in a cartographic diary as a research method. For the discussion and analysis, we conducted an ethical-aesthetic-poetic and political exercise, operating tools-concepts of schizoanalysis and the epistemology of decolonization. As a policy of this invention: a) the researcher becomes an analyzer/witness of the place of speech of black women who make up cartography from their representativeness; b) the presence of a small number of black women in health courses is an effect of the academy colonization; c) the ethical-political implication of the psychologist emerges as a device to confront institutional racism; and d) a smaller student movement becoming the common minority breaks with the instituted, creatively instituting discussions that open the debate about psychology in race relations and problem situations that emerge from the intersectionality device.
\end{abstract}

Keywords: Cartography, Racism, Psychologist's Training, Place of Speech and Representativeness, Health of Ethnic Minorities. 


\title{
Psicología de la Diferencia, Relaciones Raciales y Formación del/la Psicólogo/a
}

\begin{abstract}
Resumen: En este estudio, presentamos un informe de investigación sobre la psicología de la diferencia en las relaciones raciales, con el objetivo de mapear los procesos de subjetivación de las relaciones raciales en la formación del/la psicólogo/a y su interfaz con la práctica profesional. Como método de investigación, utilizamos la cartografía, la participación observadora, el círculo cultural y círculos de conversación para producir narrativa, relatos y escritura de sí en un diario cartográfico. Para la discusión y análisis, realizamos un ejercicio ético-estéticopoético y político, operando herramientas y conceptos del esquizoanálisis y la epistemología de la decolonización. Como política de esta invención se considera que: a) el investigador se convierte en un analizador/testigo del lugar de habla de las mujeres negras que componen la cartografía desde su representatividad; b) la presencia de un pequeño número de negras/ os en cursos de salud es resultado de la colonización de la academia; c) la implicación éticopolítica del/la psicólogo/a surge como un dispositivo para enfrentar el racismo institucional; y que d) un movimiento estudiantil más pequeño con el devenir común de la minoría rompe con lo establecido, instituyendo creativamente discusiones sobre la psicología en las relaciones raciales y las situaciones problemáticas que surgen del dispositivo de interseccionalidad.
\end{abstract}

Palabras clave: Cartografía, Racismo, Formación de Psicólogos, Lugar de Habla y Representatividad, Salud de las Minorías Étnicas.

\section{Epistemologia da decolonização e psicologia da diferença nas relações raciais}

O capitalismo global e a globalização da informação em redes sociais (Bauman, 2007; Guattari, 2002) têm produzido múltiplos efeitos na vida cotidiana, como o de ampliar a coexistência de modos de sujeição e resistência à lógica de produção de subjetividade colonial-capitalística (Rolnik, 2018). Nas palavras de Mbembe (2019), "estamos vivendo uma mudança de época ... e assistindo ao crescimento de uma grande segregação social, uma espécie de apartheid gigante" (p. 6), marcado "pela emergência de um Estado global securitário que busca normalizar um estado de exceção em escala mundial, onde ficam suspensas as noções de direito e liberdade, que eram inseparáveis do projeto de modernidade" (Mbembe, 2019, p. 7).

No Brasil, movimentos de resistência a essa lógica, ainda que espaçadamente, têm emergido como manifestações momentâneas em diferentes cenários, dos quais um dos mais marcantes foi organizado por mulheres em defesa de nossos modos de existência e contra o fascismo que nos ameaçava e continua nos ameaçando. Referimo-nos ao movimento \#EleNão, cujos atos políticos se deram em 114 cidades dos 26 estados e Distrito Federal, em 29 de setembro de 2018, inspirado pela vida e morte de Marielle Franco, mulher negra, militante e integrante da Comissão de Direitos Humanos da Assembleia Legislativa do Rio de Janeiro, que foi executada a tiros pela milícia em 14 de março de 2018 (Rocha, 2018). Outras manifestações emergiram, em 2019, durante o carnaval e as Paradas LGBTQIA+ em São Paulo e em outras cidades, contra "um governo que ... não se respeita. E que vai preparando o maior desrespeito aos direitos da população brasileira de que jamais se teve notícia ...: a desorganização geral da sociedade civil pelo Estado" (Castro, 2019, p. 6-7).

Essas manifestações, em geral, têm a arte como dispositivo. Nelas, a alegria emerge como força, pois elas atualizam "potências do desejo político das massas que apenas o contato real dos corpos é capaz de despertar, potências que, uma vez liberadas, dificilmente retornam à demência sem deixar marcas no cotidiano" (Castro, 2019, p. 12). Mbembe (2019) as concebe como políticas da visceralidade, "microinsurreições [que] ganham forma visceral como resposta à brutalização do sistema", este que produz "ausência: invisibilidade, silêncio, esquecimento" (Mbembe, 2019, p. 17). Trata-se de movimentos de "resistências [que] se organizam a partir da ocupação dos espaços, numa busca da visibilidade justo onde o poder quer nos relegar e nos afastar" (Mbembe, 2019, p. 17). Essas microinsurreições têm 
a ver com processos de subjetivação críticos, criativos e cuidantes, que expressam ruptura com assujeitamentos e constituem processos de devir sujeito; de politização do corpo e performance; de ocupação do tempo subjetivo e do espaço político, ocupação também denominada de assembleia por Judith Butler $(2017,2018)$.

Não só na África do Sul, país referido por Mbembe (2019), também no Brasil e em outros países, as resistências criativas, na contemporaneidade, "passam pela reabilitação da voz, pela expressão artística e simbólica, desafiando a tentativa do poder de relegar ao silêncio as vozes que não quer ouvir" (Mbembe, 2019, p. 17). Não obstante, no Brasil, a produção dessas novas subjetividades sensíveis ao devir minoritário estará sempre em falta com um devir indígena (Castro, 2016).

Nesse contexto, pensamos o agenciamento coletivo do desejo de resistência como produção social a partir de uma psicologia da diferença, voltada para o enfrentamento ao racismo e para a descolonização do inconsciente (Rolnik, 2018), haja vista que forja conceitos-ferramentas para que possamos negar a história contada pelo colonizador que nos anunciou e enunciar a história pela qual nos diferimos, afirmando a diferença a partir de quem somos nós, e não de quem nos anuncia (Deleuze, 2006, 2008; Foucault, 2014).

$\mathrm{Na}$ atual conjuntura política, racismo e fascismo reforçam seus alinhamentos com o capitalismo contemporâneo que "modula [a produção de subjetividade] capilarizando-se como uma linha dura nem sempre visível, partidária, instituída. Em sua versão capilar, [esses alinhamentos podem] nos fazer desejar aquilo que nos domina e explora" (Passos \& Mizoguchi, 2019, p. 9).

Na perspectiva do processo histórico e político da institucionalidade e do poder do racismo estrutural, "o Estado moderno é ou Estado racista ou ... Estado racial" (Almeida, 2019, p. 87). Para Foucault (2010a), "o racismo está ligado ao funcionamento de um Estado que é obrigado a utilizar a raça, a eliminação das raças e a purificação da raça para exercer seu poder soberano" (Foucault, 2010a, p. 217). Não obstante, na contemporaneidade, trata-se de uma versão do racismo de Estado que vem se configurando entre um Estado racista e um Estado racial, uma espécie de necrobiopoder (Bento, 2018) que se sobrepõe à biopolítica (isto é, o poder sobre a vida, sobre os corpos, sobre os desejos, uma espécie de normatização do viver) "ou de um fascismo mais difícil de localizar e, portanto, de enfrentar, já que produtor de modos de vida tristes - de vidas diminuídas em sua potência de existir" (Passos \& Mizoguchi, 2019, p. 9).

Diante disso, nossa problematização da Psicologia nas relações raciais não prescinde de uma concepção teórico-metodológica que aponta para a invenção de ferramentas-conceitos, aqui, denominada esquizoanálise (Deleuze \& Guattari, 2012). Em outras palavras, não abrimos mão de uma análise das linhas duras (molares) do racismo institucional que captam e cooptam o desejo, nem do mapeamento das linhas leves (maleáveis e moleculares) que transversalizam o corpo e apontam para a reinvenção da vida e do desejo de outro mundo possível (Deleuze \& Guattari, 2012; Guattari \& Rolnik, 2010; Rolnik, 2006; M. Santos, 2000). Desse modo, uma análise dos processos de subjetivação nas relações raciais, cuja expressão se dá em enunciados e enunciações, corresponde a uma tradução da coexistência das linhas normativas da vida e das linhas tortas e leves por meio das quais nos reinventamos e escrevemos nossa própria história.

Nessa perspectiva, apresentamos esta cartografia dos processos de subjetivação nas relações raciais por meio de narrativas, escrita e relato de si (Butler, 2015; Foucault, 2010b; Rago, 2013), que enunciam vozes de autoras negras que compõem este estudo, ora como pesquisadoras, ora como participantes. Nós autores assim como os participantes da pesquisa, negros e brancos - não temos a pretensão de representá-las. Falamos, no máximo, do lugar de testemunhas de seu lugar de fala e representatividade. Para evitar confusão entre lugar de fala e representatividade, Djamila Ribeiro (2019) concebe esse conceito como o lugar de uma composição comum a grupos sociais minoritários que produzem discursos contra hegemônicos e interrompem com o regime de autorização e normalização discursivas, refutando, assim, "a historiografia tradicional e a hierarquização de saberes consequente da hierarquia social" (Ribeiro, 2019, p. 64). Por exemplo, no âmbito dos feminismos plurais, o lugar de fala converge com o lugar de representatividade social que as mulheres negras ocupam e com o modo de articular a interseccionalidade raça, gênero, classe e sexualidade, quando estes marcadores emergem como dispositivos para colocar em análise a estrutura social (Ribeiro, 2019).

Microinsurreições e lugar de fala têm a ver com cidadania menor, pois os primeiros são modos de enfrentamento ao racismo e às injustiças sociais, a partir de devires minoritários (Guattari, 1985) 
e do desejo agenciado coletivamente por minorias em uma clínica-política do comum. Para Deleuze e Guattari (2014), esse devir minoritário é expressão de um movimento de devir outro sem se identificar com o lugar desse outro, reconhecendo-se na alteridade-solidariedade e na diferença. Portanto, criamos o conceito de cidadania menor a partir da concepção de devir minoritário (Deleuze \& Guattari, 2014) e das concepções de Milton Santos (2000) e Paulo Freire (2004). Para M. Santos (2000), não existe cidadão universal, mas existe uma cidadania que se faz a partir de um espaço enquanto território existencial. Para Freire (2004), não basta ter nascido em um lugar para ser cidadã ou cidadão de um país amparado por sua Constituição, pois a cidadania se inventa, se faz ou não se faz; logo, torna-se cidadã(o) reinventando-se ou não se experimenta a cidadania.

Partimos desse desenho teórico-metodológico para que possamos afirmar, ao fim e ao cabo, que todo racismo é institucional, haja vista que os processos de subjetivação são agenciados a partir dos efeitos que as instituições e seus regimes de verdade produzem na subjetividade e dos consequentes feitos individuais e coletivos de cada um(a).

Quando se trata de racismo de ódio como o do atual governo brasileiro, eleito para governar o país entre 2019 e 2022, pode-se dizer que o racismo é a ação do governo ou da "pessoa que se afirma ... construindo o Outro não como seu semelhante, mas como um objeto ameaçador do qual seria necessário se proteger, se desfazer ou ao qual caberia simplesmente destruir ..." (Mbembe, 2018a, p. 12). Além dessa expressão extremista de negligência, falta de respeito e desumanização que caracterizam o racismo estrutural nos âmbitos da necrobiopolítica, do fascismo e dos microfascismos, existem outras dimensões do racismo. "Segundo [o modelo proposto por] Jones (2002) ..., o racismo institucional (RI) ... desloca-se da dimensão individual e instaura a dimensão estrutural, correspondendo a formas organizativas, políticas, práticas e normas que resultam em tratamentos e resultados desiguais" (Werneck, 2016, p. 541).

Nesse contexto, como nos alerta a psicóloga e psicanalista Maria Lúcia da Silva (2017), do Movimento de Mulheres Negras, não podemos deixar de considerar a violência psicológica do racismo, na "medida em que sua lógica é reduzir, invisibilizar, criminalizar, subalternizar, inferiorizar pessoas, grupos e povos, reduzindo-os a uma condição sub-humana"
(M. L. Silva, 2017, p. 82). A autora destaca dois aspectos que a clínica psicanalista não deve negligenciar e, no nosso ponto de vista, também não deveriam ser negligenciados pelos cursos de formação de psicólogas(os) e nenhum outro curso, tampouco pelos campos de atuação da profissão. Esses dois aspectos são: a) o fato de que a ideologia da raça e as representações sociais do racismo estão na base do sistema colonial-capitalístico desde o século XVI, que constituiu o racismo estrutural e a governamentalidade na sociedade brasileira, cujas políticas públicas, em geral, beneficiam, "material e simbolicamente, os grupos nomeados como brancos" (M. L. Silva, 2017, p. 80) e negligenciam à população negra "acesso, permanência e mobilidade nas instituições” (M. L. Silva, 2017, p. 81); e b) a força dos discurso hegemônicos e da humilhação racial produzem processos de subjetivação e sujeição, deixando marcas psíquicas "de impedimentos e de manutenção de um lugar social de subordinação e inferiorização no estabelecimento das relações sociais e pessoais, funcionado como indicadores de sofrimento psíquico" (M. L. Silva, 2017, p. 87). Assim, convergimos com o pensamento de Lucas Motta Veiga (2019): "o sofrimento psíquico não é da ordem da intimidade, ele é político" (Veiga, 2019, p. 244). Por isso, o autor propõe uma psicologia preta, objetivando descolonizar o inconsciente a partir de uma escuta do mundo, de modo que "conseguir ouvir o paciente implica conseguir ouvir o sintoma que o adoece, ouvir o sintoma para ouvir o mundo que o produz" (Veiga, 2019, p. 244).

Nesse sentido, ressaltamos o conceito foucaultiano de dispositivo (Agamben, 2009), concebido como um conjunto de diferentes instituições e diversos meios que são articulados para agenciar processos de subjetivação, e afirmamos: infiltrado nas instituições, o racismo como dispositivo articulado a outros dispositivos opera por meio de visões e estigmas, jogos de saber e poder em tratamentos, atendimentos e assistência desiguais (Almeida, 2019; Ortegal, 2018; Werneck, 2016).

Para o enfrentamento ao racismo institucional, pensamos que se faz necessária a invenção de uma psicologia menor, psicologia da diferença nas relações raciais. Diante do quadro de produção de subjetividade colonial-capitalística, defendemos, então, essa psicologia da diferença, a partir de uma epistemologia da decolonização que dialoga com lugar de fala e representatividade (Ribeiro, 2019) das minorias e aposta na descolonização do inconsciente (Rolnik, 2018; Veiga, 2019) e do conhecimento (Kilomba, 2019). 
Essa epistemologia inclui “o pessoal e o subjetivo como parte do discurso acadêmico, pois todas/todos nós falamos de um tempo e um lugar específicos, de uma história e uma realidade específicas" (Kilomba, 2019, p. 58). Trata-se de "um exercício ético-estético-poético" e político de construção de conhecimento que propõe "pensar-se, conhecer-se e desconhecer-se à 'margem' do olhar imperial europeu" (Kilomba, 2019, p. 4), transformando "o conteúdo do saber e das formas de produção do saber, reativando a memória e resistindo contra o esquecimento, etc." (Mbembe, 2019, p. 17).

De certa forma, essa dimensão da Psicologia tem ganhado corpo, desde a década de 1990, com a problematização do branqueamento das raças e dos estudos culturais sobre identidade étnico-racial (A. O. Santos, Schucman, \& Martins, 2012). Não obstante, sua genealogia é anterior à Psicologia como ciência e profissão, pois está relacionada à vida cotidiana e à luta que se iniciou por meio da resistência à escravidão e dos movimentos de insurgências aos regimes colonialistas e escravistas.

Neste século XXI, somos convocadas(os) a pensar desde uma perspectiva ético-estético-poética e política, também a partir dos transfeminismos, feminismos negro e indígena, feminismo plural; das questões que envolvem políticas de demarcação de territórios existenciais indígenas e quilombolas; das políticas afirmativas, como o Estatuto da Igualdade Racial e as cotas raciais para ingresso nas Instituições de Ensino Superior (IES); da interiorização do curso de psicologia e de outros cursos da área da saúde. Estamos sendo instigados a pensar, inclusive, em como defender, sustentar ou recuperar essas conquistas.

No Brasil, a velocidade com que as relações de poder se estabeleceram, se desestabilizaram e se restabeleceram como caos - resultado das barreiras contra governos voltados para o fortalecimento das instituições democráticas e dos direitos civis, de janeiro de 2003 a março de 2016 - fez e ainda faz com que alguns agentes e representantes dos poderes executivo, legislativo e judiciário operem agenciados pelas instituições da violência (Basaglia, 2010). Agem, assim, contra as políticas de promoção da equidade em saúde (Ministério da Saúde [MS], 2013), negando o lugar de fala e representatividade das minorias em todos os setores e campos de atuação da(o) psicóloga(o), em que deveriam ser assegurados nossos direitos de existir e políticas de assistência social. A complexidade desse agenciamento atravessa a
Psicologia e as relações raciais, haja vista que a formação e a prática da(o) psicóloga(o) produzem subjetividades. Nesse campo de análise e intervenção, os processos de subjetivação expressam - por meio de gestos, enunciados e enunciações, linguagem verbal e não verbal, ora linhas de resistências singulares, ora linhas duras, molares - ódio às minorias e repúdio às diferenças de gênero, de raça, de orientação sexual e de religiosidade que podem ser sintetizados no dispositivo racismo.

Desde o início de 2019, não sem resistências, o poder executivo - com o apoio da grande mídia e do poder legislativo e com a conivência do poder judiciário e da sociedade subserviente - tem atuado cada vez mais por meio do racismo de Estado, destruindo instituições democráticas e destituindo comissões, conselhos nacionais e sistemas de direitos e seguridade social. Tal conjuntura política converge com uma necrobiopolítica (Bento, 2018), ou seja, não se trata apenas de uma biopolítica (Foucault, 2010c) efetuada por meio dos decretos e políticas do atual governo (2019-2022) que implementam uma política de controle da vida para fazer viver e deixar morrer homens e mulheres, a maioria negra, em situação de rua, de cárcere e de fome e miséria. Mas também se ocupa de executar uma política de controle da morte - necropolítica (Mbembe, 2018b) - para fazer matar e deixar matar negros(as) e indígenas nas periferias, no campo, na floresta, nas águas, além de fazer prender, fazer matar e deixar matar "a maioria" que compõe devires minoritários em todos os espaços nos quais se encontram modos de existência que resistem, ainda que à margem da produção de subjetividade colonial-capitalística, que, em geral, também fazemos questão de resistir.

Com as políticas de interiorização de cursos da área da saúde e de acesso ao ensino superior implementadas entre 2003 e 2015, as IES ganharam novas caras e cores que retratam a multiplicidade de grupos étnicos e raças existentes. Não obstante, um campo de disputa mais acirrada se instalou, devido ao incômodo que isso gerou e gera nos representantes e herdeiros do homem branco, europeu e heterossexual, imagem projetada pela crueldade do colonizador incompetente e ingênuo/arrogante (Deleuze \& Guattari, 2012) que tinha a missão de extinguir todos cuja alteridade não se deixasse identificar com a imagem do Cristo, pintado de branco, católico, apostólico e romano, ou com a imagem da Nossa Senhora Aparecida, virgem e santa pintada da cor da mulher negra africana, escravizada, explorada e abusada. 
Tais processos de semiotização, somados às interdições do corpo negro e do corpo indígena efetuadas pelos espaços instituídos de referência para o branco e o idêntico a si mesmo (como a Igreja, a Escola, o Trabalho e a Universidade), constituem uma genealogia do racismo estrutural que marca a produção de subjetividade colonial-capitalística (Rolnik, 2018).

Em um estudo sobre o estado da arte acerca do impacto do racismo na saúde mental, Damasceno e Zanello (2018) constatam que aindahá pouca contribuição da Psicologia sobre como o racismo afeta a população negra na Rede de Atenção Psicossocial. Werneck (2016) faz uma problematização das insuficiências "da saúde da população negra e da saúde da mulher negra como campos temáticos" (Werneck, 2016, p. 536) nos projetos pedagógicos dos cursos da área da saúde e na academia, bem como da ausência ou "baixo grau de penetração nas instituições de pesquisa dos debates sobre o racismo, seus impactos na saúde e suas formas de enfrentamento" (Werneck, 2016, p. 536).

O curso de Psicologia e outros cursos da área da saúde às vezes corroboram uma formação voltada à produção de subjetividade colonial-capitalística, pois o conteúdo programático das relações étnico-raciais é epistemologicamente reduzido a um tema transversal. Tal produção não está relacionada só à ideologia dos grupos sociais hegemônicos, mas também ao racismo como dispositivo que alimenta a produção do desejo no campo social ao se articular a outros dispositivos de "abrangência ampla, complexa, sistêmica, violenta" (Conselho Federal de Psicologia [CFP], 2017, p. 10), como os que emergem da análise dos processos de subjetivação. Tais dispositivos culturais, etológicos, ontológicos, midiáticos, tecnológicos, políticos, econômicos, religiosos, familiares, éticos, estéticos... (Guattari \& Rolnik, 2010) atravessam e transversalizam territórios e existências, "enfim, da vida subjetiva, vincular, social e institucional das pessoas" (CFP, 2017, p. 10).

Diante do exposto, nos perguntamos: Como profissionais da saúde pensam o lugar das relações raciais na formação e o enfrentamento ao racismo no campo de atuação? Como psicólogas(os) estão implicadas(os) e envolvidas(os) no enfrentamento ao racismo institucional? Na trilha desses questionamentos, objetivamos cartografar processos de subjetivação das relações raciais na formação da(o) psicóloga(o) e sua interface com a atuação profissional. Para compor essa cartografia, mapeamos processos de subjetivação nas relações raciais, testemunhamos e produzimos lugar de fala, conhecemos experiências e caracterizamos a implicação ético-política de profissionais da saúde. Pensamos que este relato de pesquisa pode contribuir com o debate da Psicologia em torno das questões étnicas e das relações raciais, não só com a problematização dos projetos ético-políticos da Psicologia (Yamamoto, 2012), mas também com a sugestão de reforma dos projetos político-pedagógicos de outros cursos, além de fornecer subsídios para a formação e atuação de psicólogas(os) e de outros profissionais da área da saúde nos contextos contemporâneos de enfrentamento ao racismo.

\section{Cartografia das relações raciais}

Conforme foi apresentado, este estudo versa sobre psicologia da diferença e processos de subjetivação em relações raciais. Trata-se de um relato de pesquisa feito desde a graduação dos autores, sendo um recorte de uma pesquisa mais ampla, cujo projeto foi aprovado pelo Comitê de Ética em Pesquisa (CEP) e está vinculado a nosso núcleo de estudos e a nosso programa de pós-graduação em psicologia.

A problematização do racismo institucional emerge como dispositivo em enunciados e enunciações e marca as narrativas das(os) profissionais da saúde que compõem este estudo; são narrativas de experiências em torno das relações raciais na interface formação e atuação profissional. A pesquisa foi realizada, em 2018, com a participação de 10 profissionais da saúde egressas(os) de uma IES pública e 2 futuros profissionais que cursavam Medicina na mesma instituição, perfazendo um total de 12 participantes. A composição desse campo de pesquisa está relacionada à cartografia como modo de fazer pesquisa-intervenção e como modo de produzir conhecimento por meio do desenvolvimento de práticas clínico-políticas, mapeamento de fluxos do desejo no campo social e acompanhamento dos processos de subjetivação em curso (Aguiar, 2010; Barros \& Passos, 2010; Rolnik, 2006).

A composição do campo de intervenção para análise dos processos de subjetivação deu-se por meio da participação observante e do uso das estratégias metodológicas: um círculo de cultura e duas rodas de conversa para produção de narrativas. No círculo de cultura, usamos uma poesia como objeto relacional da arte e dispositivo para acessar o plano da psicologia nas relações raciais. O tema gerador do círculo de cultura, racismo institucional, foi extraído da participação observante na IES, pelos pesquisadores 
docentes em cursos da área da saúde e pelas pesquisadoras egressas do curso de Psicologia. As narrativas produzidas no círculo de cultura foram registradas em diários cartográficos do(a) pesquisador(a) e as narrativas produzidas nas rodas de conversa foram registradas pelos(as) participantes da pesquisa em diários cartográficos de sua autoria.

\section{(Des)encontros com os resultados do racismo institucional}

A revisão sistemática de literatura realizada por P. B. G. Silva (2018) mostra como o trabalho com educação das relações étnico-raciais em instituições educacionais escolares produziu avanço em torno do reconhecimento de manifestações e consequências do racismo (P. B. G. Silva, 2018). Na contramão dos resultados dessa pesquisa, em 2016, o conteúdo programático sobre relações étnico-raciais e história e cultura afro-brasileira perdeu lugar nos parâmetros curriculares nacionais, dada a publicação da Medida Provisória (MP) no 746/2016, assinada pelo governo Michel Temer. Essa MP revogou a Lei no 10.639/2003, que assegurava a obrigatoriedade da inclusão desse conteúdo nas grades curriculares (Bittencourt, 2016).

Na IES de onde são egressas(os) as(os) profissionais da saúde participantes da pesquisa, depois da publicação da MP no 746/2016, não houve alteração em nenhum projeto pedagógico dos cursos. Contudo, no período de vigência da Lei no 10.639/2003, o debate sobre relações raciais e ensino voltado à educação étnico-racial e à saúde integral da população negra e da população indígena (MS, 2010) permaneceu distante da formação profissional, situação ainda amplamente constatada. Dos quatro cursos da área da saúde existentes na IES, apenas o curso de Medicina oferece uma disciplina optativa denominada Gênero, Diversidade e Relações Étnico-Raciais. Nos outros cursos, quando aparece, a questão é um tema transversal, ministrado segundo o critério de cada professor(a) ou de educandas(os).

A IES têm quatro cursos da área da saúde: Psicologia, Fisioterapia, Biomedicina e Medicina. Dos 12 participantes da pesquisa: 8 são psicólogas(os), 2 são biomédicas(os) e 2 estão cursando Medicina; ao todo, são 8 mulheres e 4 homens, dos quais 2 se autodeclararam brancos; dentre os homens, há 1 homem branco gay e 3 homens negros ( 1 heterossexual e 2 gays); dentre as mulheres, há 1 (uma) mulher branca e 7 mulheres negras, sendo uma lésbica, militante e defensora de uma psicologia preta.
Todas(os) são cisgênero. Para todas(os) criamos pseudônimos inspirados em nomes de mulheres negras e homens negros: Zumbi dos Palmares, Antônio Conselheiro, Cosme Bento, José Lourenço, Esperança Garcia, Zefirina, Zabé da Loca, Benedita da Silva, Clementina de Jesus, Dandara, Ruth de Souza e Matilde (homenagem à mulher negra mãe de Chico da Matilde).

No primeiro encontro, iniciamos com apresentação das(os) participantes e a leitura do poema Negro Forro, de Adão Ventura (2001): "Minha carta de alforria / Não me deu fazendas, / Nem dinheiro no banco, / Nem bigodes retorcidos. / Minha carta de alforria / Costurou meus passos / Aos corredores da noite / De minha pele". Durante o círculo de cultura, o racismo institucional emergiu como situação-problema e tema gerador. Inicialmente, isso resultou em quatro subtemas que foram debatidos, principalmente, nas duas rodas de conversa realizadas posteriormente. Esses subtemas serão apresentados na discussão; são eles: a) formação profissional; b) atuação profissional; c) racismo na saúde; e d) modos de enfrentamento ao racismo.

Os processos de subjetivação que se configuraram na leitura de mundo provocada pela leitura do poema estavam mais relacionados à dificuldade inicial de interpretação dos versos do que aos modos de pensar e teorizar das(os) participantes da pesquisa. Zabé inicia dizendo que:

O poema fala sobre o processo de abolição da escravidão mostrando que o negro foi "liberto", porém, não possuía forma de se sustentar, não conseguia emprego visto que os fazendeiros preferiam contratar os imigrantes Italianos do que contratar os negros. A segunda parte se refere à prostituição, que era uma forma de sobrevivência para os negros (Zabé).

Zumbi complementa:

Sim, o poema diz respeito a essa libertação dos escravos, visto que foram libertos mas não foram garantidos seus direitos, [os negros] continuaram sofrendo sem emprego e sofrendo discriminação. Pelo que vejo isso dura até hoje, só que de forma menos explícita (Zumbi).

Nesse sentido, conclui Zabé: "Os livros trazem a princesa Izabel como se ela tivesse sido a salvadora dos negros, mas ela não tinha escolhas, de certa forma ela foi pressionada a fazer isso". 
Não obstante, Conselheiro argumenta:

Não, o poema mostra a negação de direitos à população negra. Isso me fez lembrar das cotas onde muitas pessoas desmerecem o mérito do negro quando entra na universidade por meio das cotas, me faz pensar o quanto é necessário políticas públicas para essa população, mas também para o grupo LGBTQIA+, e o quanto falta desses assuntos serem trabalhados e discutidos nas disciplinas do campus (Conselheiro).

Nos enunciados que expressam as impressões acerca do poema e nos processos de subjetivação, como veremos, coexistem modos de subjetivação marcados pela lógica colonial-capitalística (Rolnik, 2018) e modos de subjetivação marcados pelo agenciamento coletivo do desejo de ruptura, que mostra a invenção de práticas instituintes em defesa de políticas que assegurem direitos à população negra.

Durante o círculo de cultura, nossas intervenções não podiam prescindir de uma análise que mostrasse como, em função dos regimes de verdade, ainda se atribui a outrem a conquista da liberdade; neste caso, atribui-se ao poder da soberana - princesa Isabel a abolição da escravidão. Essa expressão do agenciamento colonial-capitalístico de modos de sujeição e servidão, ainda hoje, dificulta o reconhecimento do movimento de resistência das mulheres negras e dos homens negros que produziram linhas de fuga e resistência em quilombos e por meio de insurgências na história, tais como as que marcaram a Bahia, na primeira metade do século XIX, quando, de acordo com as historiadoras Schwarcz e Starling (2015), "quilombos e práticas do candomblé se misturaram" (Schwarcz \& Starling, 2015, p. 254) e "a religião havia se transformado em linguagem política para os escravos" (Schwarcz \& Starling, 2015, p. 255).

\section{Tema gerador: relações raciais na interface formação e atuação profissional}

Na discussão dos subtemas gerados para análise dos processos de subjetivação cartografados nas rodas de conversa, por questão de espaço e recorte da pesquisa, priorizamos narrativas das(os) psicólogas(os) relacionadas ao racismo institucional. Partimos do lugar de fala e representatividade dessas(es) profissionais da saúde, egressas(os) da IES, de onde ecoam vozes que são a própria tradução das relações raciais na interface entre formação e atuação profissional. A problematização em torno da questão Psicologia nas relações raciais aparece como subtema gerador de discussão do racismo institucional. Sem dúvida, essa problemática emerge das vozes das(os) profissionais da saúde, haja vista que a maioria, ou seja, $80 \%$ das(os) egressas(os) participantes da pesquisa, é constituída por psicólogas(os).

O CFP (2017) descreve o racismo institucional como pertencente "ao nível político-programático das instituições, a ações amplas, voltadas à coletividade, cujo impacto no sujeito é posterior à ação maior, como consequência desta" (CFP, 2017, p. 48). Os resultados encontrados na pesquisa corroboram essa assertiva. Para Moraes (2013), o racismo institucional é mais facilmente identificado no âmbito da segurança e da educação, enquanto seu reconhecimento na saúde mostra-se mais difícil, haja vista que no imaginário social - composto, inclusive por quem não usa o serviço-há uma representação de que o Sistema Único de Saúde (SUS) não serve e não é bom para a população. $\mathrm{A}(\mathrm{o})$ usuária(o) ou profissional que pensa conforme essas representações desconhece o racismo como determinante social da saúde (Secretaria de Políticas de Promoção da Igualdade Racial [Seppir], 2011) e ignora quando agentes sociais, nos estabelecimentos e cenários de práticas, atuam com discriminação e preconceito diante de determinados grupos étnicos, afetando o acolhimento, o cuidado e o tratamento na assistência em saúde. Munanga (2015) afirma que "o racismo brasileiro é um racismo difuso, sutil, evasivo, camuflado, silenciado em suas expressões e manifestações" (Munanga, 2015, p. 13-14). Assim, "no plano individual, as ideologias discriminatórias, tais como o racismo e o sexismo, geram estratégias psicológicas de defesa construídas culturalmente, tais como a somatização, a negação, a racionalização e a invisibilidade para o seu enfrentamento" (Seppir, 2011, p. 11). Como consequência, tem-se que:

Saber-se negra [como afirma a psiquiatra negra Neusa Santos Souza, desde 1983] "é viver a experiência de ter sido massacrada em sua identidade, confundida em suas perspectivas, submetida a exigências, compelida a expectativas alienadas. Mas é sobretudo, a experiência de comprometer-se a resgatar sua história e recriar-se em suas potencialidades" (Tavares \& Kuratani, 2019, p. 4). 
Sobre esse sentido de tornar-se negra, escreve Matilde:

... Na universidade consegui me libertar mais dessas questões, lembro como se fosse hoje um vídeo que a professora mostrou para turma, ... nele, a poeta Mel Duarte recita o poema "Não desiste negra, não desiste!"1 ... Poesia que me sensibilizou, me deu ânimo e trouxe aquela vontade de continuar, ... continuar aprendendo, me reconhecendo, me descobrindo, me percebendo. Hoje, visualizo que esse processo se deu de dentro para fora; sim, um processo que se iniciou em meu interior, em meu peito, em meu coração há um bom tempo e que ainda continuo nesse processo de me reconhecer enquanto mulher negra (Matilde).

Para Benedita, “... O racismo institucional é uma temática complexa ...". Ela acredita "que a instituição [IES] não possua esse tipo de abordagem na formação [de profissionais da saúde]”. Pelo contrário, “... muitas vezes, existe apenas profunda apatia, ... permitindo ... que [o racismo institucional] permaneça camuflado e invisível sob outras variantes até mesmo por parte da instituição de ensino" (Benedita).

Nas palavras de Zabé:

... [Há] toda uma estrutura que parece que está enraizada. É muito difícil essa luta diária, se aparece um negro como médico, por exemplo, ele tem que se esforçar o triplo, porque tem que mostrar a competência, porque as pessoas duvidam ... Os médicos cubanos estão como prova ... (Zabé).

O pretexto da rejeição aos médicos cubanos foi ideológico; não obstante, trata-se de uma expressão do racismo estrutural que marca o inconsciente colonial-capitalístico, sustentado por um analfabetismo ético-estético-poético e político da existência que afeta a "consciência ingênua" de parte da população, (des) informada, ealimenta a perversidade da elite esquizofrênica deste país. Nas palavras de Mbembe (2018a), toda reação etnocêntrica é esquizofrênica: levanta muros, grades e mordaças em relação ao outro do outro ou à alteridade e à diferença que é sempre do outro. "Como ressaltou Deleuze, 'há sempre um negro, um judeu, um chinês, um grão-mongol, um ariano no delírio" (Mbembe, 2018a, p. 13). No caso do Brasil, despedaçado pela governabilidade político-paranoico-delirante que se iniciou em 2019, a consequência disso é que há sempre um indígena no medo de devir indígena.

O analfabetismo ético-estético-poético e político da existência, um sintoma da produção de subjetividade colonial-capitalística, configura-se como incompetência em uma zona de incapacidade ético-estético-poética e política de cuidar de si e do outro e de devir outro (minoritário) na convivência e coexistência. Trata-se de outro conceito que elaboramos a partir das concepções de consciência ingênua/ignorante (Freire, 2013), estética do oprimido (Boal, 2009) e estética da existência (Foucault, 2014). O exemplo público mais evidente e atual de analfabetismo ético-estético-poético e político da existência é o do Presidente da República (o rei que está nu), que não reconhece sua incapacidade para governar-se nem sua incompetência para ser governo dos outros.

\section{Subtema gerador: formação profissional}

Quando o subtema gerador é formação profissional, a educação em saúde emerge como um dos dispositivos de agenciamento das relações raciais. $\mathrm{Na}$ análise dos processos de subjetivação que dão conta dessa assertiva, nota-se um paradoxo. A IES não faz a problematização do tema gerador raça como um dos dispositivos que emergem da questão da interseccionalidade na determinação social dos processos de saúde-doença, tampouco pensa as relações raciais como um dispositivo que nos faz ver e falar da determinação social da saúde. Então, por um lado, alguns docentes tomam os elementos desses dispositivos isoladamente como categorias estanques em resultados de pesquisas ou para justificar projetos de extensão; por outro lado, uma militância estudantil menor, vinculada a movimentos sociais minoritários e periféricos, pauta, nos contextos acadêmicos, o tema do racismo institucional a partir de seu lugar de fala e representatividade, relacionando-o à raça, ao gênero, à sexualidade e à classe.

Clementina reconhece que se falou de racismo "em alguns momentos ao longo da graduação [em psicologia], em específico na disciplina de Ética profissional". Zefirina confirma que foram “... aulas expositivas sobre a temática ..." e denuncia: “... durante a formação, os[as] profissionais da área da saúde não são orientados[as] a como agir/reagir diante do racismo".

\footnotetext{
${ }^{1}$ https:/www.youtube.com/watch?v=FfDvjbsCFmM
} 
Em uma pesquisa realizada por Costa e M. C. R. Silva (2017), em Fortaleza, os resultados indicam que a discussão sobre relações étnico-raciais no ensino superior, na maioria das vezes, fica concentrada e limitada em apenas um ou outro professor e, quando ultrapassa esses limites, deriva de um movimento dos próprios alunos interessados na temática. No ponto de vista de Clementina:

O papel da psicologia [nas relações raciais], levando em consideração um posicionamento ético-político, é o de estar sempre desconstruindo práticas que promovam a violência. Acredito que se algo afeta negativamente a vida do outro, é preciso mudar e o racismo é fruto de um contexto histórico e cultural que ainda hoje assola, embora, às vezes, seja de maneira velada; portanto, não negar a existência já é um modo de enfrentamento (Clementina).

Para Conselheiro: "A formação abriu olhares e discussões para o enfrentamento ao racismo de um modo periférico, mas que despertou indagações ao respeito de não existir disciplinas e discussões mais persistentes e sistemáticas no sentido de conhecimento jurídico para enfrentamento ao racismo".

É a primeira vez que a instituição Justiça emerge como dispositivo na análise dos processos de subjetivação; sem dúvida, os conceitos-ferramentas da psicologia jurídica também podem ser acionados para o enfrentamento ao racismo. Os atravessamentos que marcam os processos de subjetivação, como mostram as próximas narrativas de experiências, nos remetem à interseccionalidade e às questões econômicas, sociais e de acesso à educação, ao trabalho e à renda, como dispositivos da determinação social da saúde e da ampliação ou diminuição das desigualdades raciais.

Esperança, ao avaliar o contexto da IES em que concluiu o curso, percebe "que poucos ainda são [negras]/ negros; mostrando que apesar da existência de ações afirmativas, como por exemplo as cotas, a população negra ainda éminoria". Ruth narra, em seu diário cartográfico:

Em 5 anos de curso, racismo nunca foi tema de aula, nunca se abordou por parte da instituição o racismo como atravessamento na produção de pobreza e adoecimento. Professores não se aproximam do tema de forma crítica, pelo contrário, alguns chegam a querer vim com conversa meritocrática, repugnante. Todas as movimentações e questionamentos vieram por parte dos estudantes nesse quesito (Ruth).

A meritocracia é um indicador de racismo e agencia processos de subjetivação de professores(as), agentes que operam linhas duras, molares. "Tal hierarquia introduz uma dinâmica na qual a negritude significa não somente 'inferioridade', mas também 'estar fora do lugar' enquanto abranquitude significa 'estar nolugar' e, portanto, superioridade” (Kilomba, 2019, p. 56).

Nos processos de subjetivação dos agentes marcados pelo racismo acadêmico, "corpos negros são construídos como corpos impróprios, como corpos que estão 'fora do lugar' e, por essa razão, corpos que não podem pertencer" (Kilomba, 2019, p. 56) ao campo de produção de conhecimento.

Não obstante, na mesma IES denunciada por Ruth, ela anuncia a potência de ação do movimento estudantil menor que aciona outros dispositivos e produz processos de subjetivação singulares, expressando linhas da vida, maleáveis e moleculares, ao agir de forma crítica, criativa e cuidante diante de situações-problema relacionadas às relações raciais, ao racismo e à (in)justiça social. A problematização do discurso meritocrático mostra a resistência da minoria que compõe a representatividade da população negra e periférica dentre os muros da IES. Uma educanda negra, ao ocupar o lugar de fala em um movimento de devir minoritário, torna-se, pela representatividade, capaz de compor um coletivo que produz rupturas nas práticas político-pedagógicas que operam uma lógica colonial-capitalística. Esse agenciamento coletivo do desejo dessa minoria produz fissuras nos muros invisíveis que sustentam as instituições da violência quando, em suas intervenções para enfrentamento ao racismo institucional, levam em consideração outros dispositivos que são articulados na produção de subjetividades e modos de devir sujeito; são modos de resistência que se contrapõem aos modos de sujeição e servidão que impedem ou dificultam o acesso da população negra e de outros grupos minoritários ao ensino superior, aos serviços de saúde e à saúde como direito básico.

\section{Subtema gerador: atuação profissional}

Quanto à atuação profissional em múltiplos setores e diversos contextos, encontramos convergências com as referências técnicas produzidas pelo CFP (2017) para atuação da(o) psicóloga(o). 
A transversalidade marca essa produção de subjetividades e os processos de subjetivação mostram implicações éticas com a profissão e compromisso ético-político com a vida, apontando para a produção de modos de romper com o racismo institucional e para modos de superar as iniquidades existentes dentro e fora dos estabelecimentos de saúde. Pensando nessa perspectiva, Esperança surpreende-se:

Nossa! Vejo na prática [da(o) psicóloga(o)] a possibilidade, a oportunidade de resistência, de me manifestar enquanto mulher negra, de lutar contra todos os tipos de desrespeito, de preconceitos $e$ também de possibilitar a troca de informações de conscientização sobre o assunto, potencializar as ações de combate nesse sentido (Esperança).

A implicação ético-política da(o) psicóloga(o) também aponta para o sofrimento ético-político (Sawaia, 2008) como um dispositivo para pensar as relações raciais e para problematizar os efeitos do racismo institucional. O sofrimento ético-político interfere na produção da vida cotidiana e mostram como a dor e o adoecimento são efeitos das injustiças sociais (Sawaia, 2008) e como o racismo na saúde opera uma lógica excludente, por meio da qual um corpo social hegemônico deslegitima o corpo negro. Não obstante, o corpo negro é capaz de devir corpo negro na encruzilhada de caminhos e enfrentamento ao racismo. Ou seja, há sempre um corpo negro que existe e resiste movendo-se no mundo da diáspora com seus múltiplos devires, compondo cartografais nômades entre aporias, dizibilidades e (in)visualidades na construção de um processo de devir autora/ autor entre o lúdico, o poético e o teórico (Ávila \& Ferla, 2017; ÒkòTó, 2018).

Na gestão do trabalho e educação em saúde, encontra-se um dos maiores desafios para atuação da(o) psicóloga(o): lidar com sujeitas(os) inseridas(os) em situações de injustiças sociais, desigualdades socioeconômicas e, consequentemente, numa histórica falta de acesso à saúde, educação, assistência, moradia e transporte público de qualidade, realidades estas infelizmente ainda bastante prementes entre grande parte da população negra em decorrência de como a escravidão e o racismo operaram (e ainda operam) em nosso país, inclusive como determinante social da saúde. Nesse sentido, afirma Benedita:
A presença de poucos negros na saúde, como sabemos, é um reflexo do processo de elitização de alguns cursos que têm como combustivel a injustiça social, parcela da população negra é de classe social baixa e apresenta problemas socioeconômicos sérios que contribuem para o contexto atual, mas as intervenções sociais são uma ferramenta importante que podem estar a amenizar essa realidade (Benedita).

Outras narrativas reforçam essa leitura de mundo. Mundo no qual a população negra enfrenta maiores dificuldades que a população branca no acesso à educação, além de receber salários mais baixos do que os salários do branco. Sem dúvida, a implicação ético-política passa pela implicação com a produção da vida, na qual a promoção da saúde (MS, 2006) está marcada por atravessamentos que também agenciam os processos de saúde-doença e sua determinação social, envolvendo questões econômicas de classe, segurança alimentar e questões do mundo do trabalho como emprego e renda, além dos dispositivos já mencionados: etnia, raça, gênero, sexualidade e classe.

\section{Subtema gerador: racismo na saúde}

Os processos de subjetivação das(os) profissionais da saúde giram em torno de uma ética do cuidado nas relações raciais e da problematização do racismo institucional como determinante social da saúde. Dos 12 participantes, nove delas(es), ou seja, $75 \%$, afirmam não ter presenciado manifestações de racismo no campo de estágio; três, ou seja, $25 \%$, disseram já ter presenciado em sua atuação profissional.

Esperança argumenta: “... é inegável as conquistas advindas da luta e combate ao racismo e a todos os tipos de preconceito, mas infelizmente ainda vivencio e presencio algumas cenas, nos vários campos onde ando ...". Ruth também afirma:

Não [vi] diretamente, como se imagina que seria o racismo clássico, com xingamentos e agressão física. Mas presenciei o racismo institucional, onde serviços que se dispõem a ser "de saúde pública e universal" negligenciam comunidades com maior população negra, com profissionais pouco sensíveis aos recortes étnicos e aos fatores históricos de vulnerabilização (Ruth). 
Não podemos esquecer componentes dos processos de semiotização, ditos não verbais, tais como gestos, olhares, outras expressões do rosto e do corpo, o silêncio e o silenciamento, haja vista que muitas vezes são produtores de sofrimento. Maria Jesus Moura (2018) denuncia esse silêncio como efeito não só da educação de pais e mães, muitas vezes negros, mas sobretudo de uma escravidão psíquica, ou seja, do racismo como uma "estratégia para destruir, criar pessoas controladas, sem autonomia, que não consigam ter um discernimento". Com larga experiência em atendimento a mulheres negras, a psicóloga diz que a maioria chega ao consultório sem conseguir nomear o racismo nas relações sociais e, consequentemente, tem maiores dificuldades em reconhecer os processos psicossociais do racismo e seus efeitos na saúde mental. De acordo com a autora:

A cordialidade do racismo no Brasil produz efeitos devastadores para as relações raciais. Até onde se silencia sobre as diferenças raciais, as relações são mantidas sem conflito, mas se o pacto de silêncio é quebrado as relações são estremecidas, e aquilo que era lindo, exótico, charmoso, até mesmo sensual, torna-se promíscuo, feio, defeituoso, vulgar (Moura, 2009, p. 46).

Portanto, faz-se necessário pensar essas questões na formação profissional para que também na atuação sejam consideradas várias questões que produzem sofrimento. Assim, espera-se que se saiba lidar com as diferenças, a fim de contribuir para a produção da saúde a partir dos grupos étnicos e do contexto no qual a população está inserida, respeitando a cultura, os conhecimentos, a religiosidade, os gêneros, as classe e as raças.

Sobre o racismo na saúde, Ruth argumenta que:

... está para além de falta de informação, pois há muita informação sim, logo, é uma questão de violência mesmo. Quando uma criança negra tem $60 \%$ de chances a mais de morrer antes dos 5 anos por doenças ridículas que criamos remédios e tratamentos eficientes para combater há mais de um século atrás, nãoéquestão de doença simples e pura,équestão de: qual o sistema, a ideologia violência que está matando, por negligência, essas crianças? (Ruth).

Esperança desabafa: "Me sinto envergonhada $e$ muito triste, por isso ainda acontecer, ao passo de juntar força para que de alguma forma esse racismo diminua, para que estejamos cientes dos nossos direitos, para que não haja omissão diante de um ato tão lamentável". Quando a vergonha (Sawaia, 2008) como afecção do corpo é acionada, funciona como dispositivo de controle social para diminuir a potência de ação. Não obstante, Esperança busca e encontra força na vida e na consciência crítica dos direitos humanos, a fim de questionar o Estado pelas omissões ante as iniquidades.

O racismo articulado aos dispositivos classe, religião, gênero e orientação sexual, agencia os modos de subjetivação e produz subjetividades. As(os) profissionais da saúde reconhecem que o racismo é produtor de sofrimento e o quanto a instituição Saúde pode influenciar no processo de adoecimento, de descaso e negligência, que em alguns casos, como os citados por Ruth, podem levar ao óbito.

\section{Subtema gerador: modos de enfrentamento ao racismo}

Quanto aos modos de enfrentamento ao racismo institucional, a implicação ética da(o) psicóloga(o) emerge como dispositivo nos processos de subjetivação das(os) profissionais. A maioria se refere às microinsurgências produzidas pelo movimento estudantil menor no âmbito das relações raciais, durante a formação.

Zefirina, mulher branca, psicóloga e heterossexual, não confunde seu lugar de fala com o lugar de fala e representatividade da mulher negra. Ela reconhece que "o racismo institucional existe e é visível aos olhos de quem o queira ver" e afirma: “... não é uma temática bastante discutida na academia, mas acredito que há estratégias na psicologia que possam servir para o enfrentamento ao racismo ... através da defesa dos direitos humanos ...". Além dessa aposta na defesa dos direitos humanos no enfrentamento ao racismo, Benedita reconhece que "as intervenções sociais são uma ferramenta importante que podem estar a amenizar essa realidade". No enfrentamento ao racismo, Lourenço aponta a necessidade de "uma militância para que se mude efetivamente" o quadro de exclusão, negligência e iniquidades.

Zabé, ao se referir aos modos de enfrentamento ao racismo institucional por negligência política da IES, declara: "os movimentos universitários existentes no campus [eram e são os que] traziam e trazem consciência de si", provocando discussões que ultrapassam uma identidade segmentada e a própria população negra. Ela refere-se às minorias: "seja LGBTQIA+, feministas, 
negros, mulheres negras, grupos trans". A maioria das (dos) profissionais da saúde cita uma das pesquisadoras deste estudo como exemplo de militância e trabalho de resistência dentro e fora dos muros da IES.

\section{Relações raciais: cartografias finais}

Neste estudo, apresentamos uma cartografia da Psicologia e relações raciais na interface formação e atuação profissional. Anunciamos as concepções de analfabetismo ético-estético-poético e político da existência e de cidadania menor e operamos ferramentas-conceitos de uma epistemologia da decolonização. Nesta perspectiva, iniciamos a sistematização da discussão e análise com uma teorização de nossa terceira autora, cujo lugar de fala e representatividade foram lembrados pela maioria das(os) participantes, durante o círculo de cultura e as rodas de conversa. Ela escreve:

Primeiramente, como mulher, negra, militante e psicóloga, já existo enquanto ofensa a uma sociedade racista e misógina. Minha prática profissional é reflexo do meu posicionamento político e ético no campo social. A Psicologia se propõe, em suas várias facetas, a cuidar de gente, e não há como fazer isso sem entender que existem recortes e leituras que precisam ser feitas. Minha implicação na luta contra o racismo vem do fato de ter que lidar com ele todos os dias. Mas isso não quer dizer que os psicólogos e psicológicas brancos não devam lutar também.

Por meio desta cartografia, caracterizamos o racismo institucional e outros dispositivos que compõem seu agenciamento: raça, gênero, sexualidade, etnia e classe. Mapeamos modos de singularização no enfrentamento ao racismo institucional, como movimentos feministas, feministas negras, movimento LGBTQIA+ e movimento negro. Os processos de subjetivação que contornam as intervenções nos fazem ver e falar da força desses pequenos agenciamentos coletivos do desejo existentes no processo de devir grupo-sujeito. Não obstante, não se configuram como microinsurreições no âmbito da formação e atuação profissional, mas compõem uma micropolítica do desejo do movimento estudantil minoritário, cujos processos de singularização expressam modos de romper com o instituído, instaurando discussões que suscitam o debate em torno da psicologia nas relações raciais e de outras situações-problema, que estão para além dos muros da IES, principalmente das instituições da violência. Trata-se de um devir comum minoritário que produz pequenas fissuras nesses muros, apontando para a composição de movimentos micropolíticos de enfrentamento ao racismo e de resistência à produção de subjetividades colonial-capitalística (Guattari \& Rolnik, 2010; Rolnik, 2018).

No âmbito da análise da IES, a presença de uma psicóloga negra e militante, ora como discente (em passado recente), ora como pesquisadora, funciona como analisador das relações raciais na interface formação e atuação profissional. As(os) participantes desta pesquisa, ao compor esta cartografia, puderam devir grupo-sujeito e cada um(a) também pode devir autora/autor ao narrar experiências, por meio de relato e escrita de si. Ogrupo-sujeito revela como o pesquisador-analisador (mulheres negras que assinam este artigo como segunda e terceira autoras), por meio do exercício ético-estético-poético e político, pode contribuir com a produção de estratégias de enfrentamento ao racismo, mostrando como faz sentido ocupar lugar de fala e representatividade.

No projeto de sociedade no qual o Estado de exceção tem substituído o Estado democrático de direito, como assinalamos com as palavras de Mbembe (2019) na introdução deste artigo, noções de que "somos todos iguais, com direitos e deveres iguais" ficam perdidas, bem como a evasiva "ordem e progresso" e o mantra "igualdade, liberdade e fraternidade" que alimentou o projeto de modernidade por muitos anos. A problematização do racismo institucional, nessa conjuntura política de exceções, nos faz pensar o quão necessário é um projeto ético, estético, poético e político de sociedade (Passos \& Mizoguchi, 2019) e como a Psicologia, voltada a esse projeto, poderia contribuir para uma ética da alteridade-solidariedade no cuidado em saúde.

\section{Referências}

Agamben, G. (2009). O que é o contemporâneo? e outros ensaios (V. N. Honesko, Trad.). Argos.

Aguiar, L. M. (2010, 2-6 de setembro). As potencialidades do pensamento geográfico: a cartografia de Deleuze e Guattari como método de pesquisa processual [Trabalho apresentado]. XXXIII Congresso Brasileiro de Ciências 
da Comunicação, Caxias do Sul. https://edisciplinas.usp.br/pluginfile.php/4047519/mod_resource/content/0/ Deleuze\%20e\%20o\%20me\%CC\%81 todo\%202.pdf

Almeida, S. (2019). Racismo estrutural. Pólen.

Ávila, M. Y. B., \& Ferla, A. A. (2017). O que pode o corpo? Corpografias de resistência. Interface: Comunicação, Saúde, Educação, 21(62), 731-748. https://doi.org/10.1590/1807-57622016.0898

Barros, R. D. B., \& Passos, E. (2010). A Cartografia como método de pesquisa-intervenção. In E. Passos, V. K. \& L. da Escóssia (Orgs.), Pistas do método de cartografia: Pesquisa-intervenção e produção de subjetividade (2a ed., pp. 17-31). Sulina.

Basaglia, F. (2010). Escritos selecionados em saúde mental e reforma psiquiátrica. Garamond.

Bauman, Z. (2007). Tempos líquidos (C. A. Medeiros, Trad.). Zahar.

Bento, B. (2018). Necrobiopoder: Quem pode habitar o Estado-nação? Cadernos Pagu, (53), 1-16. https://doi.org/ $10.1590 / 18094449201800530005$

Bittencourt, C. M. (nov. 2016). A MP 746/2016 e o impacto no ensino da história e cultura afro-brasileira. Jus.com.br. https://jus.com.br/artigos/54207/a-mp-746-2016-e-o-impacto-no-ensino-da-historia-e-cultura-afrobrasileira

Boal, A. (2009). A estética do oprimido. Garamond.

Butler, J. (2015). Relatar a si mesmo: Crítica da violência ética (R. Bettoni, Trad.). Autêntica.

Butler, J. (2017). A vida psíquica do poder: Teorias da sujeição (R. Bettoni, Trad.; 1a ed.). Autêntica.

Butler, J. (2018). Corpos em aliança e a política das ruas: Notas para uma teoria performativa de assembleia (F. S. Miguens, Trad.; 1a ed.). Civilização Brasileira.

Castro, E. V. (2016). Os involuntários da pátria.n-1 edições.

Castro, E. V. (2019). Brasil, o país do futuro do pretérito. n-1 edições.

Conselho Federal de Psicologia. (2017). Relações raciais: Referências técnicas para atuação de psicólogas(os).

Costa, E. B., \& Silva, M. C. R. (2017). Reflexões sobre as relações étnico-raciais no ensino superior. In G. C. Silva, M. S. Lopes \& R. M. P. Monteiro (Orgs.), Experiências em ensino, pesquisa e extensão na universidade: Caminhos e perspectivas (Vol. 2, pp. 107-121). Imprece.

Damasceno, M. G., \& Zanello, V. M. L. (2018). Saúde mental e racismo contra negros: Produção bibliográfica brasileira dos últimos quinze anos. Psicologia: Ciência e Profissão, 38(3), 450-464. https://doi.org/ $10.1590 / 1982-37030003262017$

Deleuze, G. (2006). Cinco proposições sobre a psicanálise. In G. Deleuze, A ilha deserta: e outros textos (C. V. Silva, Trad., pp. 345-352). Iluminuras.

Deleuze, G. (2008). Conversações (P. P. Pelbart, Trad.). Editora 34.

Deleuze, G., \& Guattari, F. (2012). Mil platôs: Capitalismo e esquizofrênia (A. Guerra Neto, A. L. Oliveira, L. C. Leão \& S. Rolnik, Trads.; Vol. 3). Editora 34.

Deleuze, G., \& Guattari, F. (2014). Kafka: Por uma literatura menor (C. V. Silva, Trad.). Autêntica.

Foucault, M., (2010a). Aula de 17 de março de 1976. In M. Foucault, Em defesa da sociedade (M. E. Galvão, Trad., 2a ed., pp. 201-222). WMF Martins Fontes.

Foucault, M. (2010b). Aula de 6 de janeiro de 1982. In M. Foucault, A Hermenêutica do sujeito (3a ed., pp. 3-24). WMF Martins Fontes.

Foucault, M., (2010c). História da sexualidade: A vontade de saber (M. T. C. Albuquerque \& J. A. G. Albuquerque, Trads.; Vol. 1). Edições Graal.

Foucault, M. (2014). Genealogia da ética, subjetividade e sexualidade (Vol. 9). Forense Universitária.

Freire, P. (2004). Pedagogia da tolerância. Editora Unesp.

Freire, P. (2013). Educação como prática da liberdade. Paz e Terra.

Guattari, F. (1985). Revolução Molecular: Pulsações políticas do desejo (S. Rolnik, Trad.; 3a ed.). Brasiliense. 
Félix-Silva, A. V., Duque, J. P., Santos, J. S. dos, Rocha, M. B. da, \& Severo, A. K. de S. (2022). Psicologia da diferença e relações raciais.

Guattari, F. (2002). As três ecologias (M. C. F. Bitencourt, Trad.; 13a ed.). Papirus.

Guattari, F., \& Rolnik, S. (2010). Micropolítica: Cartografias do desejo (10a ed.). Vozes.

Kilomba, G. (2019). Quem pode falar? Falando do centro, descolonizando o conhecimento. In G. Kilomba, Memórias da plantação: Episódios de racismo cotidiano (J. Oliveira, Trad., pp. 47-69). Cobogó.

Mbembe, A. (2018a). O Fardo da Raça. Entrevistas com Achille Mbembe a A. Fargeau \& C. Portevin. n-1 edições.

Mbembe, A. (2018b). Necropolítica: Biopoder, soberania, estado de exceção, política de morte (R. Santini, Trad.; 2a ed.). n-1 edições.

Mbembe, A. (2019). Poder brutal, resistência visceral (D. Kaus, Trad.). n-1 edições.

Ministério da Saúde. (2006). Política Nacional de Promoção da saúde.

Ministério da Saúde. (2010). Política Nacional de Saúde Integral da População Negra: Uma política para o SUS.

Ministério da Saúde. (2013). Políticas de Promoção da Equidade em Saúde.

Moraes, F. (2013). No país do racismo institucional: Dez anos de ações do GT Racismo no MPPE. Procuradoria Geral de Justiça de Pernambuco.

Moura, M. J. (2009). A produção de sentidos sobre violência racial no atendimento psicológico a mulheres que denunciam violência de gênero [Dissertação de mestrado, Universidade Federal de Pernambuco]. Attena Repositório Digital da UFPE. https://repositorio.ufpe.br/handle/123456789/8361

Moura, M. J. (13 jul. 2018). "Para você não romper o silêncio e manter as relações saudáveis, você tem que negar a sua cor". Entrevista com Maria de Jesus Moura. El País. https://brasil.elpais.com/brasil/2018/07/06/ politica/1530885070_540009.html

Munanga, K. (2015). Por que o racismo e suas práticas e qual é a responsabilidade social que se espera dos profissionais que lidam com as questões da sociedade? Revista Brasileira de Psicologia, 2(n. esp.), 7-15.

ÒkòTó, D. İ. M. (2018). O Corpo negro é um corpo encruzilhada: Não existe caminho fechado, mas caminho a se abrir com decisão e sacrifício. Blog do autor. https://dessalin-okoto.medium. com/o-corpo-negro-\%C3\%A9-um-corpo-encruzilhada-ca8082e34bee

Ortegal, L. (2018). Relações raciais no Brasil: colonialidade, dependência e diáspora. Serviço Social \& Sociedade, (133), 413-431. https://doi.org/10.1590/0101-6628.151

Passos, E., \& Mizoguchi, D. H. (2019). Antifascismo tropical. n-1 edições.

Rago, L. M. (2013). A aventura de contar-se: Feminismos, escrita de si e invenções da subjetividade. Editora da Unicamp.

Ribeiro, D. (2019). Lugar de fala. Sueli Carneiro; Pólen.

Rocha, L. M. (2018). Apresentação. In M. Franco, UPP: A redução da favela a três letras: Uma análise da política de segurança do estado do Rio de Janeiro (pp. 11-15). n-1 edições.

Rolnik, S. (2006). Cartografia sentimental: Transformações contemporâneas do desejo. Estação Liberdade.

Rolnik, S. (2018). Esferas da insurreição: Notas para uma vida não cafetinada. n-1 edições.

Santos, A. O., Schucman, L. V., \& Martins, H. V. (2012). Breve histórico do pensamento psicológico brasileiro sobre relações étnico-raciais. Psicologia: Ciência e Profissão, 32(n. esp.), 166-175. https://doi.org/10.1590/ S1414-98932012000500012

Santos, M. (2000). Por uma outra globalização: Do pensamento único à consciência universal. Record.

Sawaia, B. B. (2008). O sofrimento ético-político como categoria de análise da dialética exclusão/inclusão. In B. B. Sawaia (Org.), As artimanhas da exclusão: Análise psicossocial e ética da desigualdade social (10a ed., pp. 97-118). Vozes.

Schwarcz, L. M., \& Starling, H. M. (2015). Brasil: Uma biografia. Companhia das Letras.

Secretaria de Políticas de Promoção da Igualdade Racial. (2011). Racismo como determinante social da saúde.

Silva, M. L. (2017). Racismo no Brasil: Questões para psicanalistas brasileiros. In N. M. Kon, M. L. Silva \& C. C. Abud (Orgs.), O racismo e o negro no Brasil (pp. 71-89). Perspectiva.

Silva, P. B. G. (2018). Educação das relações étnico-raciais nas instituições escolares. Educar em Revista, 34(69), 123-150. https://doi.org/10.1590/0104-4060.58097 
Tavares, J. S. C., \& Kuratani, S. M. A. (2019). Manejo clínico das repercussões do racismo entre mulheres que se “tornaram negras". Psicologia: Ciência e Profissão, 39. https://doi.org/10.1590/1982-3703003184764

Veiga, L. M. (2019). Descolonizando a psicologia: notas para uma Psicologia Preta. Fractal: Revista de Psicologia, 31(n. esp.), 244-248. https://doi.org/10.22409/1984-0292/v31i_esp/29000

Ventura, A. (2001). Negro forro. In I. Moriconi (Org.), Os cem melhores poemas brasileiros do século (pp. 275). Objetiva.

Werneck, J. (2016). Racismo institucional e saúde da população negra. Saúde e Sociedade, 25(3), 535-549. https:// doi.org/10.1590/s0104-129020162610

Yamamoto, O. H. (2012). 50 anos de profissão: Responsabilidade social ou projeto ético-político? Psicologia: Ciência e Profissão, 32(n. esp.), 6-17. https://doi.org/10.1590/S1414-98932012000500002

\section{Antonio Vladimir Félix-Silva}

Professor do Programa de Pós-graduação em Psicologia da Universidade Federal do Piauí, Campus Ministro Reis Velloso (UFPI) e do curso de medicina da Universidade Federal do Delta do Paranaíba (UFDPar), Parnaíba - PI. Brasil. Vinculado à linha de pesquisa Psicologia, Saúde Coletiva e Processos de Subjetivação do PPGPsi/UFPI. Membro do grupo de pesquisa Política, Produção de Subjetividade e Práticas de Resistência (UFRN). Doutor em Ciências Psicológicas pela Universidade de Havana, Cuba.

E-mail: wladyfelix@hotmail.com

(1) https://orcid.org/0000-0003-3084-379X

\section{Jéssica Pereira Duque}

Psicóloga do Centro de Referência em Assistência Social (CRAS), São João dos Patos - MA. Brasil. Graduada em Psicologia pela Universidade Federal do Piauí (UFPI), Parnaíba - PI. Brasil.

E-mail: jessyca_pduque@outlook.com

(1) https:/ / orcid.org/0000-0001-6818-8319

\section{Joice Silva dos Santos}

Graduada em Psicologia pela Universidade Federal do Piauí (UFPI), Parnaíba - PI. Brasil. Pós-graduanda em Saúde Pública e da Família na Faculdade de Tecnologia Evolução (Fecet), Fortaleza - CE. Brasil. Pós-graduada em Direitos Humanos pela Faculdade Adelmar Rosado (FAR), Teresina - PI. Brasil.

E-mail: joicesantos_psi@outlook.com

(1) https://orcid.org/0000-0001-5681-6947

\section{Matheus Barbosa da Rocha}

Professor do curso de Psicologia da Universidade Federal do Piauí (UFPI), Parnaíba - PI. Brasil. Mestre pelo Programa de Pós-graduação em Psicologia da UFPI (PPGPsi/UFPI), Parnaíba - PI. Brasil. Doutorando no Programa de Pós-graduação em Psicologia da Universidade Federal do Rio Grande do Norte (UFRN).

E-mail: matheusbr.psico@live.com

(1) https:/ / orcid.org/ 0000-0003-2483-1100

\section{Ana Kalliny de Sousa Severo}

Professora da Faculdade de Ciências da Saúde (Facisa) da Universidade Federal do Rio Grande do Norte (UFRN), Santa Cruz-RN. Brasil.Vinculada ao grupo de pesquisa Política, Produção de Subjetividade e Práticas de Resistência da UFRN). Doutora em Saúde Coletiva pela Universidade Estadual de Campinas (Unicamp), Campinas - SP. Brasil. E-mail: kallinysevero@yahoo.com.br

(1) https:/ / orcid.org/0000-0002-9548-6394 
Endereço para envio de correspondência:

Universidade Federal do Delta do Paranaíba (UFDPar). Av. São Sebastiao, 2819, Nossa Senhora de Fatima. CEP: 64202-020. Parnaíba - PI. Brasil.

Recebido 14/10/2019

Aceito 03/08/2021

Received 10/14/2019

Approved 08/03/2021

Recibido 14/10/2019

Aceptado 03/08/2021

Como citar: Félix-Silva, A. V., Duque, J. P., Santos, J. S. dos, Rocha, M. B. da, \& Severo, A. K. de S. (2022).

Psicologia da diferença, relações raciais e formação da(o) psicóloga(o). Psicologia: Ciência e Profissão, 42, 1-17. https://doi.org/10.1590/1982-3703003229977

How to cite: Félix-Silva, A. V., Duque, J. P., Santos, J. S. dos, Rocha, M. B. da, \& Severo, A. K. de S. (2022). Psychology of the difference, race relations and psychologist's training. Psicologia: Ciência e Profissão, 42, 1-17. https://doi.org/10.1590/1982-3703003229977

Cómo citar: Félix-Silva, A. V., Duque, J. P., Santos, J. S. dos, Rocha, M. B. da, \& Severo, A. K. de S. (2022). Psicología de la diferencia, relaciones raciales y formación del/la psicólogo/a. Psicologia: Ciência e Profissão, 42, 1-17. https://doi.org/10.1590/1982-3703003229977 